University of South Florida

DIGITAL COMMONS

Digital Commons @ University of

@ UNIVERSITY OF SOUTH FLORIDA

South Florida

9-2009

\title{
Mean Dynamic Topography of the Ocean Derived from Satellite and Drifting Buoy Data Using Three Different Techniques
}

\author{
Nikolai Maximenko \\ University of Hawaii \\ Peter Niiler \\ University of California \\ Marie-Helene Rio \\ Collecte Localisation Satellites \\ Oleg Melnichenko \\ University of Hawaii \\ Luca Centurioni \\ University of California
}

See next page for additional authors

Follow this and additional works at: https://digitalcommons.usf.edu/msc_facpub

Part of the Marine Biology Commons

\section{Scholar Commons Citation}

Maximenko, Nikolai; Niiler, Peter; Rio, Marie-Helene; Melnichenko, Oleg; Centurioni, Luca; Galperin, Boris; Chambers, Don. P.; and Zlotnicki, Victor, "Mean Dynamic Topography of the Ocean Derived from Satellite and Drifting Buoy Data Using Three Different Techniques" (2009). Marine Science Faculty Publications. 191.

https://digitalcommons.usf.edu/msc_facpub/191

This Article is brought to you for free and open access by the College of Marine Science at Digital Commons @ University of South Florida. It has been accepted for inclusion in Marine Science Faculty Publications by an authorized administrator of Digital Commons @ University of South Florida. For more information, please contact digitalcommons@usf.edu. 


\section{Authors}

Nikolai Maximenko, Peter Niiler, Marie-Helene Rio, Oleg Melnichenko, Luca Centurioni, Boris Galperin, Don.

P. Chambers, and Victor Zlotnicki 


\title{
Mean Dynamic Topography of the Ocean Derived from Satellite and Drifting Buoy Data Using Three Different Techniques*
}

\author{
Nikolai Maximenko, ${ }^{+}$Peter Niller, ${ }^{\#}$ Marie-Helene Rio, ${ }^{@}$ Oleg Melnichenko, \& \\ LuCA Centurioni, ${ }^{\#}$ DOn Chambers, ${ }^{* *}$ Victor Zlotnicki, ${ }^{+}+{ }^{+}$AND Boris GAlperin $\#$ \\ ${ }^{+}$International Pacific Research Center, School of Ocean and Earth Science and Technology, \\ University of Hawaii at Manoa, Honolulu, Hawaii \\ \# Scripps Institution of Oceanography, University of California, San Diego, La Jolla, California \\ @ Collecte Localisation Satellites, Ramonville Saint-Agne, France \\ \& International Pacific Research Center, School of Ocean and Earth Science and Technology, \\ University of Hawaii at Manoa, Honolulu, Hawaii, and Marine Hydrophysical Institute, \\ National Academy of Sciences of Ukraine, Sevastopol, Ukraine \\ ** Center for Space Research, The University of Texas at Austin, Austin, Texas \\ ++ Jet Propulsion Laboratory, California Institute of Technology, Pasadena, California \\ \#\# College of Marine Science, University of South Florida, St.Petersburg, Florida
}

(Manuscript received 24 September 2008, in final form 6 February 2009)

\begin{abstract}
Presented here are three mean dynamic topography maps derived with different methodologies. The first method combines sea level observed by the high-accuracy satellite radar altimetry with the geoid model of the Gravity Recovery and Climate Experiment (GRACE), which has recently measured the earth's gravity with unprecedented spatial resolution and accuracy. The second one synthesizes near-surface velocities from a network of ocean drifters, hydrographic profiles, and ocean winds sorted according to the horizontal scales. In the third method, these global datasets are used in the context of the ocean surface momentum balance. The second and third methods are used to improve accuracy of the dynamic topography on fine space scales poorly resolved in the first method. When they are used to compute a multiyear time-mean global ocean surface circulation on a $0.5^{\circ}$ horizontal resolution, both contain very similar, new small-scale midocean current patterns. In particular, extensions of western boundary currents appear narrow and strong despite temporal variability and exhibit persistent meanders and multiple branching. Also, the locations of the velocity concentrations in the Antarctic Circumpolar Current become well defined. Ageostrophic velocities reveal convergent zones in each subtropical basin. These maps present a new context in which to view the continued ocean monitoring with in situ instruments and satellites.
\end{abstract}

\section{Introduction}

Historical compilations of persistent ocean surface currents present a picture where the poleward flowing western boundary currents and their seaward extensions are narrow and fast and the midocean currents, including the Antarctic Circumpolar Current, are broad and slow

\footnotetext{
* International Pacific Research Center Publication Number 576 and School of Ocean and Earth Science and Technology Publication Number 7656.

Corresponding author address: Nikolai Maximenko, IPRC/ SOEST, University of Hawaii at Manoa, 1680 East West Road, POST Bldg. \#401, Honolulu, HI 96822.

E-mail: maximenk@hawaii.edu
}

(Richardson 1989). In the later part of the twentieth century, as ocean water mass properties were measured on ever-smaller scales (Siedler et al. 2001, 193-204) and continuous shipborne instruments for direct ocean velocity observations became available, finer scales of the midocean variability became exposed (Rudnick 1996). This regional sampling of the ocean on the mesoscale, at about $50-\mathrm{km}$ resolution, revealed a very different picture. The midocean became dense with eddies and fronts (Robinson 1983), but the persistence of many of these mesoscale features, because of lack of repeated sampling, could not be determined. Here, we combine new global geophysical datasets and identify many new features of the ocean surface mesoscale circulation that have persisted for over a decade. 
For the past $15 \mathrm{yr}$, two complementary ocean observing systems have been in operation. From these observations, a near-surface ocean velocity field can be calculated on a repeat basis. Systematic observations of the motion of near-surface satellite-tracked drifters began in 1988 (Niiler 2001a). These observations made it possible to compute significant time-mean currents at mesoscale resolution in the North Atlantic, where the data were sufficiently dense (Reverdin et al. 2003). The drifter observations provide direct measurements of local near-surface ocean currents. However, they can be sparse and heterogeneous in space and time, rendering time averages over a mesoscale global grid fraught with possible sampling bias. Since 1992, multiple satellites carrying ocean radar altimeters have provided regular observations of sea surface height with near-mesoscale resolution (Pascual et al. 2006). The altimetry data are used here in two different ways. First, the difference between a time-averaged sea surface height from altimetry and the geoid (a specific equipotential surface of the earth's gravity field) from the Gravity Recovery and Climate Experiment (GRACE) yields one estimate of $\bar{\eta}_{A}$, the time-averaged or mean dynamic topography (MDT). Removal of the gravity signal is essential because it is one to two orders of magnitude larger than $\bar{\eta}_{A}$ itself (Wunsch and Gaposchkin 1980; Zlotnicki and Marsh 1989; Nerem et al. 1990). Second, the time variability $\eta^{\prime}$ is used to calculate geostrophic velocity (Stammer 1997) to remove sampling bias in the drifter data. The latter is due to a highly heterogeneous distribution of the Lagrangian dataset by the deployment scheme and affected by divergent Ekman currents at the ocean surface (Maximenko and Niiler 2008).

The horizontal momentum equation at the ocean surface (Gill 1982),

$$
\frac{d \mathbf{V}}{d t}+\mathbf{k} \times f \mathbf{V}=-g \nabla\left(\bar{\eta}+\eta^{\prime}\right)+\frac{1}{\rho} \frac{\partial \boldsymbol{\tau}}{\partial z},
$$

will be used here to combine these datasets, where $\mathbf{V}$ is the water velocity; $\mathbf{k}$ is the vertical unit vector; $f$ is the Coriolis parameter; $g$ is the acceleration resulting from gravity; $\bar{\eta}$ and $\eta^{\prime}$ are the time-mean and time-variable dynamic topographies, respectively; $\rho$ is the density of the seawater; and $\partial \tau / \partial z$ is the vertical divergence of horizontal turbulent stress $\tau$.

The first term on the left-hand side of Eq. (1) is the acceleration following water particles. It is nonlinear in the velocity $\mathbf{V}$ components and their spatial gradients. Calculations from drifter data show that it is small compared to other terms in the equation, except very near the equator or on time scales shorter than several days (Ralph et al. 1997). Because the horizontal turbulent stress $\tau$ does not appear to depend on the sea level gra- dient $\nabla \eta$ (Large 1998), the velocity $\mathbf{V}$ can be decomposed into geostrophic and Ekman components, respectively,

$$
\mathbf{V}=\mathbf{V}_{G}+\mathbf{V}_{E}
$$

such that

$$
\begin{gathered}
\mathbf{k} \times f \mathbf{V}_{G}=-g \nabla \eta \quad \text { and } \\
\mathbf{k} \times f \mathbf{V}_{E}=\frac{1}{\rho} \frac{\partial \boldsymbol{\tau}}{\partial z}
\end{gathered}
$$

Analogous decomposition was tested south of Japan by Uchida et al. (1998) and Imawaki et al. (2001) and over the North Pacific by Uchida and Imawaki (2003). Equations similar to Eqs. (3) and (4) are used by Ocean Surface Current Analysis-Real time (OSCAR; available online at http://www.oscar.noaa.gov/) to compute surface velocity from satellite sea level and wind data.

Until recently, the geoid has not been known with the accuracy sufficient to measure $\bar{\eta}$ on mesoscale. Several new, highly accurate global geoid models with improved spatial resolution up to 300-500 $\mathrm{km}$ have been created using the data from the GRACE mission (Tapley et al. 2004). In method $A$, we use $\bar{\eta}_{A}$ computed as the difference of the Goddard Space Flight Center Mean Sea Surface 2000 (GSFCMSS00) time-mean sea surface and GRACE Gravity Model 2002 (GGM02C) geoid models (available online at http://grace.jpl.nasa.gov/data/dot/; Tapley et al. 2003; Fig. 1a).

Our study begins with this and a similar (Rio and Hernandez 2004) satellite-based $\bar{\eta}_{A}$ and refines them to mesoscale resolution using drifter, $\eta^{\prime}$, and wind data. First, the drifter velocity, satellite sea level anomaly, and ocean winds are used to derive statistical formulas regressing the Ekman velocity linearly to the concurrent wind. Then, the Ekman component is subtracted from the drifter velocity and the geostrophic component resulting from Eq. (2) is used in Eq. (3) or Eq. (1) to compute two MDTs for the global ocean. Two MDTs are presented that produce mesoscale features that are quite independent of the details of method B, which is described by Rio and Hernandez (2004), or method C, which is a new development of the methodology introduced by Niiler et al. (2003). The combination of the drifter and satellite data yields ocean dynamic topography patterns at a spatial resolution higher than that achievable today from satellite data alone and with better intermediate and long wavelength accuracy than those obtainable from drifter data alone.

\section{Mean circulation at $15-\mathrm{m}$ depth}

Mesoscale features of the global near-surface circulation appear in the time-average motion of drifters that were 

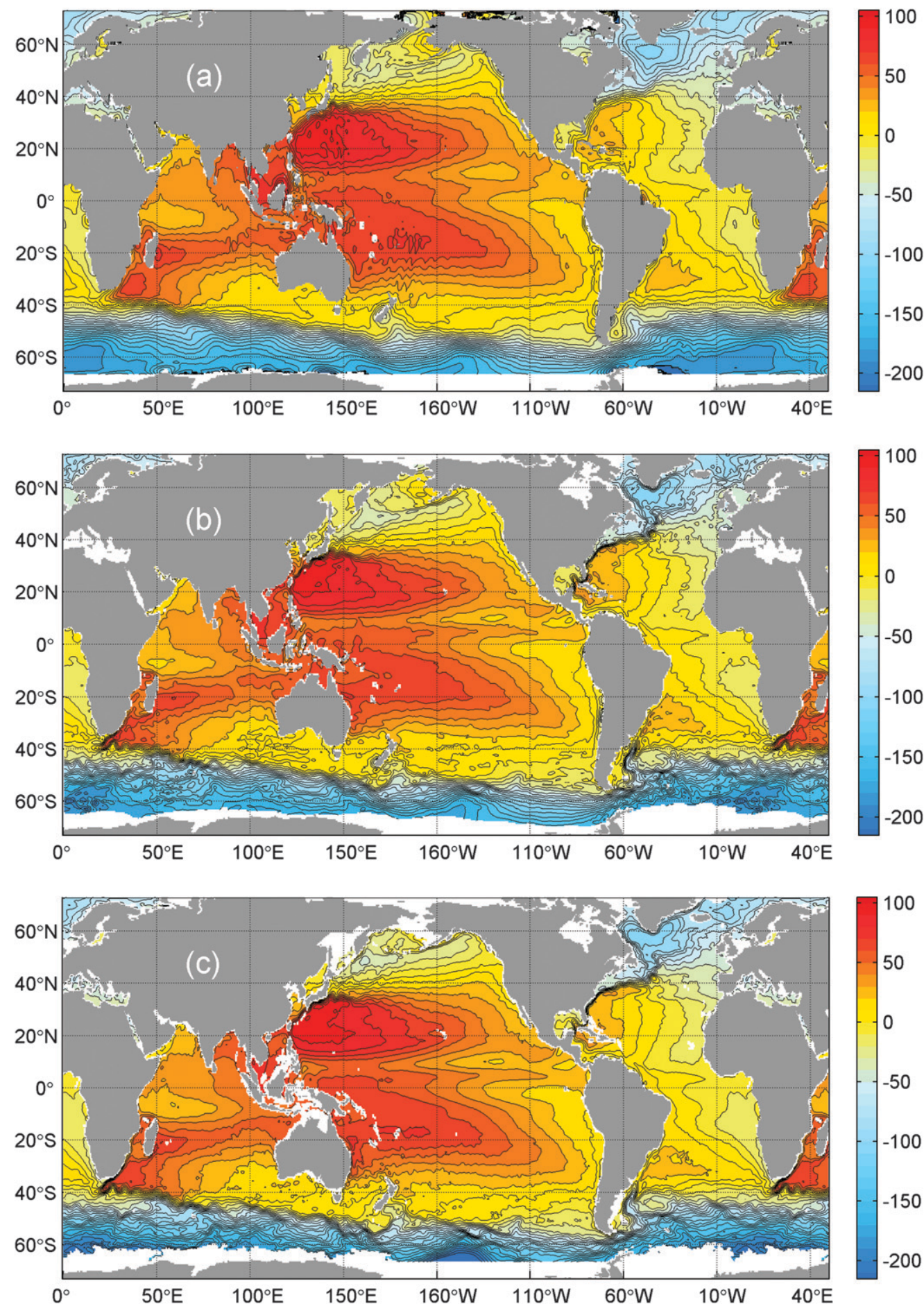

FIG. 1. Maps of mean dynamic topographies (a) $\bar{\eta}_{A}$, (b) $\bar{\eta}_{B}$, and (c) $\bar{\eta}_{C}$ calculated with methods A, B and C, respectively, as described in the text. All figures are adjusted to the period $1993-2002$. The contour interval is $10 \mathrm{~cm}$.

drogued to $15-\mathrm{m}$ depths. Figure 2a shows mean streamlines and color-coded velocity magnitudes calculated from the ensemble-averaged drifter velocities collected by the National Oceanic and Atmospheric Administration
(NOAA) Atlantic Oceanographic and Meteorological Laboratory (AOML) from February 1979 through April 2007. Data are averaged in $0.25^{\circ}$ boxes and smoothed with a $1^{\circ} \times 1^{\circ}$ moving mean filter. 

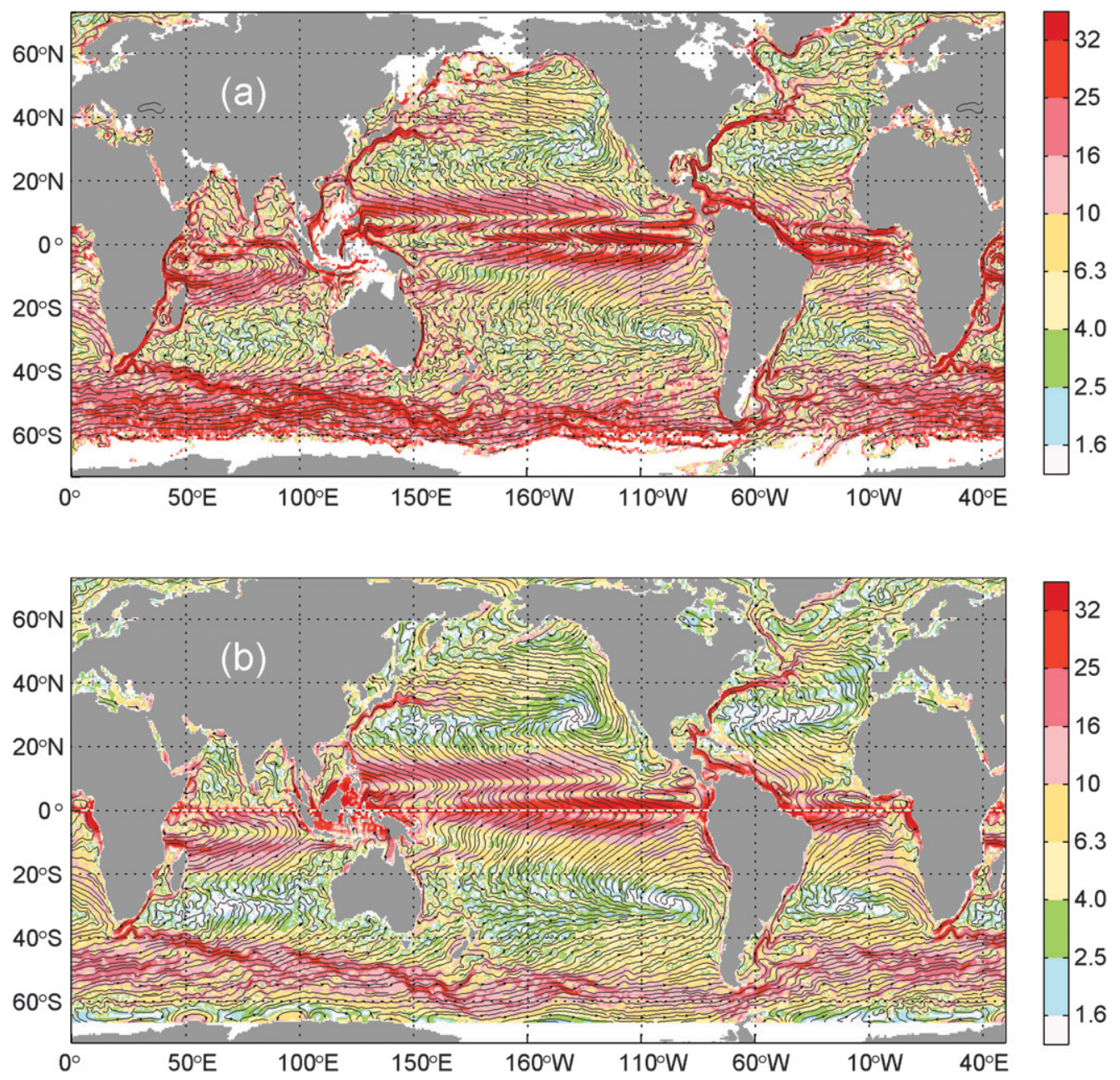

FIG. 2. Mean streamlines calculated from (a) $0.25^{\circ}$ ensemble-mean velocities of the drifters drogued at $15-\mathrm{m}$ depth between $15 \mathrm{Feb} 1979$ and 1 May 2007 smoothed to $1^{\circ}$ and (b) a combination of the mean geostrophic and Ekman velocities with method $\mathrm{C}$ described in the text. The choices of streamlines are made in an iterative fashion to cover the ocean at relatively uniform, several-degree-scale spatial density, giving the preference to the longest lines. Colors are magnitudes of (a) mean drifter velocity and (b) mean geostrophic plus Ekman velocity used to compute the streamlines, and units are $\mathrm{cm} \mathrm{s}^{-1}$.

The flow patterns depicted in Fig. 2a reveal all known subtropical western boundary currents and their meandering seaward extensions. The Agulhas Extension has as least five persistent meanders (Pazan and Niiler 2004). The longest continuous boundary current flows along the western margin of the Atlantic-from south of the equator, along the coast of northern Brazil, along the south coast of the Caribbean, through the Gulf of Mexico, and along the east coast of Florida-to become the Gulf Steam at Cape Hatteras, North Carolina (Schmitz and Richardson 1991). The Antarctic Circumpolar Current system is marked with a number of near-zonal circulation concentrations or accelerations, which will be discussed later.
In the tropics and subtropics, the streamlines that begin in regions of strong divergence along the equator extend poleward and end up in the convergences in the middle of subtropical gyres. Spiraling convergences appear at $30^{\circ} \mathrm{N}, 140^{\circ} \mathrm{W}$ and $30^{\circ} \mathrm{S}, 100^{\circ} \mathrm{W}$. The northeast Pacific spiral (Sverdrup et al. 1942) is now recognized as a vast area of aggregation of plastic debris (San Francisco Chronicle, 6 November 2006; available online at http://www.sfgate.com/cgi-bin/article.cgi?file $=/ \mathrm{c} / \mathrm{a} /$ 2006/11/06/OCEANS.TMP). The South Pacific spiral, shown here for the first time, is a graveyard of about 150 drifters. The well-known tropical and subtropical zonal currents are seen as local eastward (e.g., North Equatorial Countercurrent) or westward (e.g., North Equatorial Current) accelerations of particles that are 


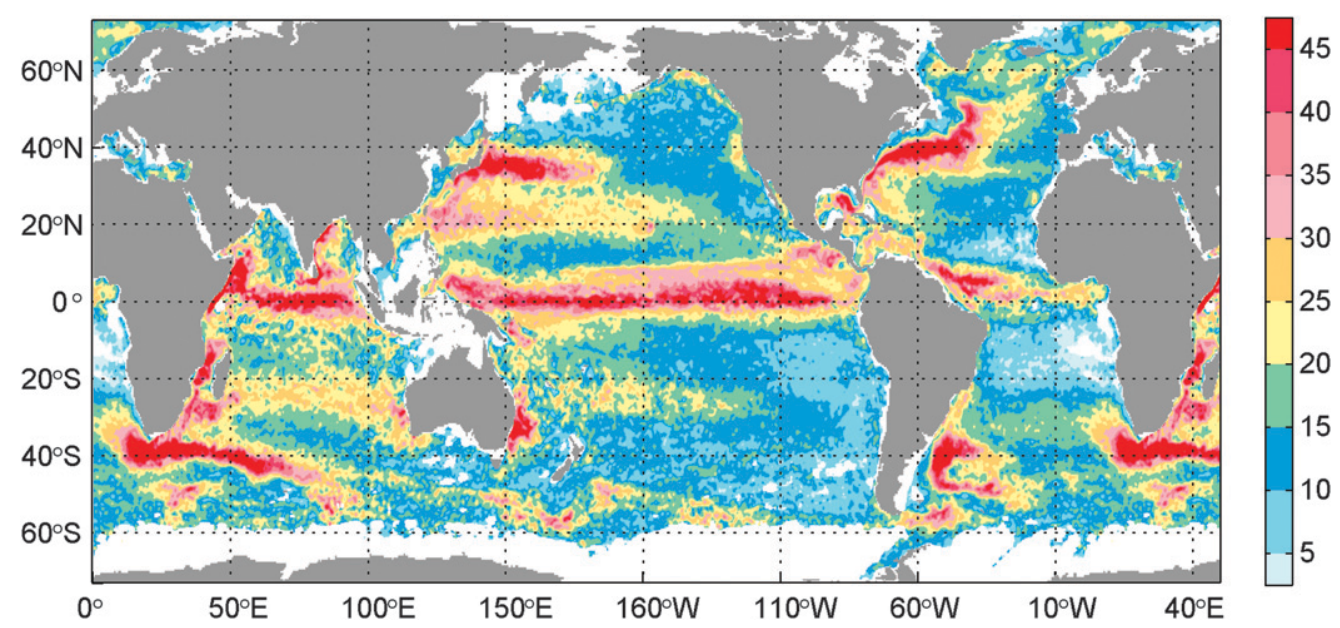

FIG. 3. The rms deviation of the drifter velocity from the local ensemble mean shown in Fig. 2a. Units are $\mathrm{cm} \mathrm{s}^{-1}$.

generally flowing in the poleward direction from the equator to converge in the centers of the subtropical doldrums.

\section{Ekman currents}

To calculate $\bar{\eta}$ from the drifter data, first, wind-driven Ekman currents must be isolated. In method B (Rio and Hernandez 2003), parameterizations for monthly mean Ekman velocities in $5^{\circ}$ latitude bins were derived. These parameterizations were used in this study with 6-hourly European Centre for Medium-Range Weather Forecasts (ECMWF) reanalysis surface wind stress. Thus obtained Ekman velocities were interpolated to drifter locations and subtracted from the observed total drifter velocities. Then, a 3-day low-pass filter was applied to yield a geostrophic drifter velocity.

In method C (Maximenko and Niiler 2005), the rightmost terms in the momentum balance Eq. (1) are calculated from drifter and satellite data by regressing them onto the vector winds according to

$$
\frac{d \mathbf{V}}{d t}+\mathbf{k} \times f \mathbf{V}+g \nabla \eta^{\prime}+g \nabla \bar{\eta}_{A}=C \cdot \mathbf{R}(\alpha) \cdot \mathbf{W},
$$

where $\eta^{\prime}$ is the Archiving, Validation and Interpretation of Satellite Oceanographic data (Aviso) sea level anomaly (SLA; Ducet et al. 2000), $\bar{\eta}_{A}$ is the GRACE-based MDT of method A (Tapley et al. 2004), $\mathbf{R}(\alpha)$ is the rotation matrix, and $\mathbf{W}$ is the 6-hourly, 10-m height NCEP reanalysis wind (data available online at http://www.cdc. noaa.gov/data/gridded/data.nmc.reanalysis.html). The coefficient $C$ and the rotation angle $\alpha$ are determined from the $1^{\circ}$ latitude band ensembles of the 6-hourly data across the entire ocean basins, including the equator. This model of the wind force, as expressed on the right- hand side of Eq. (5), is used to compute the wind force collocated with the drifter.

The computation of the Ekman velocity in method B is biased toward periods between 3 and 20 days, and the regression of the Ekman wind force in method $\mathrm{C}$ is biased toward steady winds. In all cases, spatial scales of the Ekman currents correspond to atmospheric scales and generally are much larger than the oceanic mesoscale.

\section{Temporal variability of currents}

The variance of the velocity components changes over the ocean by more than three orders of magnitude. Its distribution in Fig. 3 displays, besides the energetic equatorial regions, large values also near western and eastern continental boundaries, near islands (e.g., Hawaii and Canary), and near midocean ridges in the subpolar oceans exemplified by the four regions of enhanced variance that fan out from the Gulf Stream extension in the North Atlantic. The distribution of variance is produced by near-geostrophic velocity in concentrated areas, where the root-mean-square (rms) velocity is larger than $10 \mathrm{~cm} \mathrm{~s}^{-1}$, and by Ekman currents in large areas of "eddy deserts." Variability of Ekman currents is commonly smaller than eddy variability.

Natural variability of the ocean causes noise in the average of heterogeneous observations. This noise can be significantly reduced if currents are in geostrophic equilibrium or in more complex balance described by Eq. (1). The drifter geostrophic velocity obtained in the previous section consists of a time-mean component required for the subsequent construction of the MDT and an anomaly. The $\eta^{\prime}$ from Aviso can be used to subtract the anomaly, provided a significant correlation exists between $\eta^{\prime}$ and the drifter geostrophic velocity (Crosby 


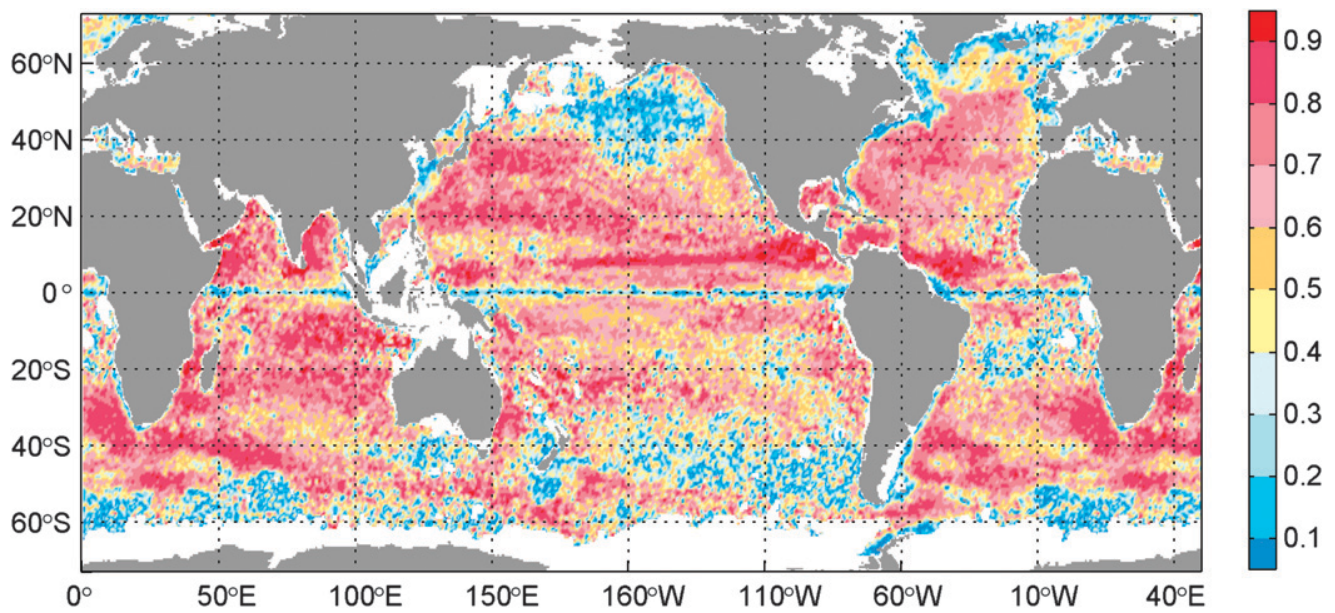

FIG. 4. The correlation $\left\langle\mathbf{V}_{\mathrm{DG}}^{\prime} \mathbf{V}_{\mathrm{AG}}^{\prime}\right\rangle /\left[\left\langle\mathbf{V}_{\mathrm{DG}}^{\prime} \mathbf{V}_{\mathrm{DG}}^{\prime}\right\rangle\left\langle\mathbf{V}_{\mathrm{AG}}^{\prime} \mathbf{V}_{\mathrm{AG}}^{\prime}\right\rangle\right]^{1 / 2}$ between the anomalies of collocated drifter geostrophic velocity $\mathbf{V}_{\text {DG }}^{\prime}$ and Aviso-derived altimetric geostrophic velocity $\mathbf{V}_{\text {AG }}^{\prime}$. Anomaly here is the deviation from the ensemble mean.

et al. 1993). As shown in Fig. 4, there are vast regions of the subtropical gyres, the Antarctic Circumpolar Current, and near-equatorial areas where the vector correlation of the geostrophic balance terms exceeds 0.50 . In these regions, nearly every time-variable mesoscale feature that was observed by drifters during the years 1992-2006 was also mapped by Aviso $\eta^{\prime}$ (Pascual et al. 2006).

It is important to note that a detailed comparison of Figs. 3 and 4 reveals the regions where ocean current variability is not resolved by the Aviso $\eta^{\prime}$ [e.g., IcelandFaeroes Front (Niiler et al. 1992)], the residual variability is not in geostrophic balance (Centurioni et al. 2008), or near-surface currents are steady (Niiler 2001b) or weak (Fig. 2). Even in regions where the correlation in Fig. 4 is below 0.5 , the drifter data effectively define the mean flow on scales pertinent to this study.

\section{Mean dynamic topographies}

In method B, synthetic time-mean velocities and mean dynamic topography estimates are used to improve a first guess through an objective analysis and compute the MDT on a $0.5^{\circ}$ latitude by $1^{\circ}$ longitude grid. The analytical correlation functions between these variables are derived from the geostrophic momentum balance (Rio and Hernandez 2004; Rio et al. 2005). The first guess is a large-scale MDT field based on the EIGEN02S geoid model (Reigber et al. 2005) and the Collecte Localisation Satellites 2001 (CLS01) mean sea surface (Hernandez et al. 2001). The time-mean geostrophic velocities are computed by subtracting the Aviso anomaly of geostrophic velocity from the instantaneous drifter geostrophic velocity. CTD and XBT profiles are used to compute dynamic heights relative to $1500 \mathrm{dbar}$. The missing barotropic and deep baroclinic components are reconstructed as an approximate difference between the first guess and the climatological field referenced to $1500 \mathrm{~m}$ (Levitus et al. 1998). The altimetric $\eta^{\prime}$ is then subtracted to obtain synthetic estimates of the MDT. When using XBT data, the missing salinity records are restored with the mean temperaturesalinity $(T-S)$ relationship (Guinehut and Larnicol 1999; Guinehut 2002). Relative errors in each variable are used to weigh the contribution of each field to the MDT. The resulting subsampled map of MDT $\left(\right.$ or $\left.\bar{\eta}_{B}\right)$ on a $0.5^{\circ} \times 0.5^{\circ}$ grid is shown in Fig. $1 b$.

In method C, the MDT (now labeled $\bar{\eta}_{C}$ ) is derived by minimizing the global cost function,

$$
\Phi=\oiint_{\text {drifters }}\left|\nabla \bar{\eta}_{C}-\langle\nabla H\rangle\right|^{2} d S+\frac{4 \pi^{2}}{L^{2}} \oiint_{\text {global }}\left(\bar{\eta}_{C}-\bar{\eta}_{A}\right)^{2} d S+\delta^{2} \oiint_{\text {global }}\left(\nabla^{2} \bar{\eta}_{C}\right)^{2} d S,
$$

where $L=2000 \mathrm{~km}$ and $\delta$ is close to the grid size.

The estimator of the MDT gradient $\langle\nabla H\rangle$ is a gridded ensemble average of

$$
\langle\nabla H\rangle=\frac{-\left\langle\frac{d \mathbf{V}}{d t}+f \mathbf{k} \times \mathbf{V}+g \nabla \eta^{\prime}-C \cdot R(\alpha) \cdot \mathbf{W}\right\rangle}{g},
$$


which is calculated from the 6-hourly collocated data of drifters, SLA, and wind. The map of $\bar{\eta}_{C}$ is presented in Fig. 1c (data are available online at http://apdrc.soest. hawaii.edu/projects/DOT). It can be shown (Maximenko and Niiler 2005) that, on scales larger than $L, \bar{\eta}_{C}$ is strongly controlled by $\bar{\eta}_{A}$, whereas on smaller scales it is mostly defined by the drifter-derived velocity. Laplacian smoothing is added to reduce the grid noise. If not blended with $\bar{\eta}_{A}$ [the second term in the right-hand side of Eq. (6)], $\bar{\eta}_{C}$ closely follows the mean dynamic topography of Niiler et al. (2003), which tends to slightly overestimate the sea level difference across the main large-scale gyres and Antarctic Circumpolar Current.

The MDTs $\bar{\eta}_{B}$ and $\bar{\eta}_{C}$-derived with methods $\mathrm{B}$ and C, respectively-produce remarkably consistent pictures, with a global rms difference of $6.5 \mathrm{~cm}$. The largest difference is south of $55^{\circ} \mathrm{S}$; if this area is excluded, then a 4.1-cm rms difference results. Methods B and C can be viewed as adding small-scale signal to $\bar{\eta}_{A}$. This does not change the pattern of large-scale geostrophic circulation (cf. Figs. 1a,c), and the rms difference between $\bar{\eta}_{C}$ and $\bar{\eta}_{A}$ is $7.3 \mathrm{~cm}$, which is small compared to the range of $\bar{\eta}_{C}$. Yet, this difference is concentrated at small scales and produces differences in spatial gradients and corresponding geostrophic velocities. The rms velocities derived from $\bar{\eta}_{C}$ and $\bar{\eta}_{A}$ outside the $5^{\circ}$ equatorial band are 8.9 and $6.9 \mathrm{~cm} \mathrm{~s}^{-1}$, respectively. The rms of the difference between the two velocities is $6.7 \mathrm{~cm} \mathrm{~s}^{-1}$. For comparison, $\bar{\eta}_{B}$ yields the rms velocity of $8.5 \mathrm{~cm} \mathrm{~s}^{-1}$, while the rms difference between the $\bar{\eta}_{B}$ - and $\bar{\eta}_{C}$-produced velocities is $4.2 \mathrm{~cm} \mathrm{~s}^{-1}$. The denser concentration of sea level isolines in Figs. 1b,c highlights the fact that practically all current systems are sharper and faster than one would deduct from Fig. 1a. The difference between $\bar{\eta}_{A}$ and $\bar{\eta}_{C}\left(\right.$ or $\left.\bar{\eta}_{B}\right)$ is particularly evident in geostrophic velocities shown in Fig. 5. Although the velocities calculated from $\bar{\eta}_{A}$ are broader and weaker than the ones from $\bar{\eta}_{B}$ and $\bar{\eta}_{C}$, inherent spatial noise contributes significantly to obscuring the difference in the energy levels of the currents estimated above.

Equation (2) suggests that a mean velocity can be constructed by adding Ekman and geostrophic velocities. Figure $2 \mathrm{~b}$ shows the map of such a circulation pattern calculated from $\bar{\eta}_{C}$ and $C, R(\alpha)$, and NCEP $10-\mathrm{m}$ winds averaged over the period of 1993-2002. The correspondence between Figs. 2a,b is quite remarkable, thus demonstrating the validity of Eq. (2). The largest difference between the total and the geostrophic nearsurface flow paths (Fig. 1c) is attained in the tropics where the mean streamlines move away from the equator while the geostrophic streamlines move toward the equator. Generally, the mesoscale features, discernible in both Figs. 1b,c, appear in all oceans and are nearly identical.
To a large extent, this is due to the direct observations of velocity with drifters used in both methods described in this paper. Moving eastward with the steady meandering pattern of the Agulhas Current extension off the tip of the South Africa (Ochoa and Niiler 2007), at least eight regions of highly concentrated, or accelerated, eastward flows of the Antarctic Circumpolar Current system can be identified in both Figs. 1 and 2. These flow features are real, because their near-surface vorticity balance can be understood combining the dynamics of standing Rossby waves and their interaction with the underlying topographic features (Hughes 2005).

\section{New features on the map of ocean circulation}

The zonal geostrophic mean velocities computed from $\bar{\eta}_{A}, \bar{\eta}_{B}$, and $\bar{\eta}_{C}$ were selectively colored in Fig. 5 to enhance values between 1 and $10 \mathrm{~cm} \mathrm{~s}^{-1}$. This highlights many small-scale features that are embedded in the broader flows. Each of the features can be traced back to drifter velocities, where, however, they are not as well defined because of the eddy noise and Ekman currents. The pattern of the near-surface geostrophic velocity is also interesting because it is expected to have subsurface extension, perhaps, well into the ocean thermocline.

In the North Pacific and North Atlantic, south of the seaward extensions of the western boundary current are westward flows, or the southern limbs of the Kuroshio Extension and Gulf Stream recirculations. In both oceans, a pattern of alternating striations continues southward. In the North Atlantic, the eastward striation at approximately $35^{\circ} \mathrm{N}$ is the Azores Current (Juliano and Alves 2007), now for the first time seen to be extending westward to the longitude of Bermuda at $72^{\circ} \mathrm{W}$. North of it in Fig. 5c is a coherent eastward striation, heretofore not described, that connects the Mann Eddy (Mann $1967)$ to the coast of Portugal along $40^{\circ} \mathrm{N}$. A clockwise flow is visible around the Reykjanes Ridge at $60^{\circ} \mathrm{N}$ as are the Iceland-Faeroes Islands Front and the Norwegian Current farther to the north and east.

In the western North Pacific, the eastward striation at approximately $22^{\circ} \mathrm{N}$ is known as the Subtropical Countercurrent (Uda and Hasunuma 1969), but the westward striation north of it has not been described before. North of the Hawaiian Islands at $24.5^{\circ} \mathrm{N}$ is an eastward striation that was observed with expendable velocity probes in 1985 (Niiler et al. 1991) to extend well below the main thermocline, but its persistence was not realized until now. The pair of alternating striations in Figs. 5b,c west of the Hawaiian Islands is known as the Hawaiian Lee Countercurrent (Xie et al. 2001). The Kuroshio Extension and the Gulf Stream extension 

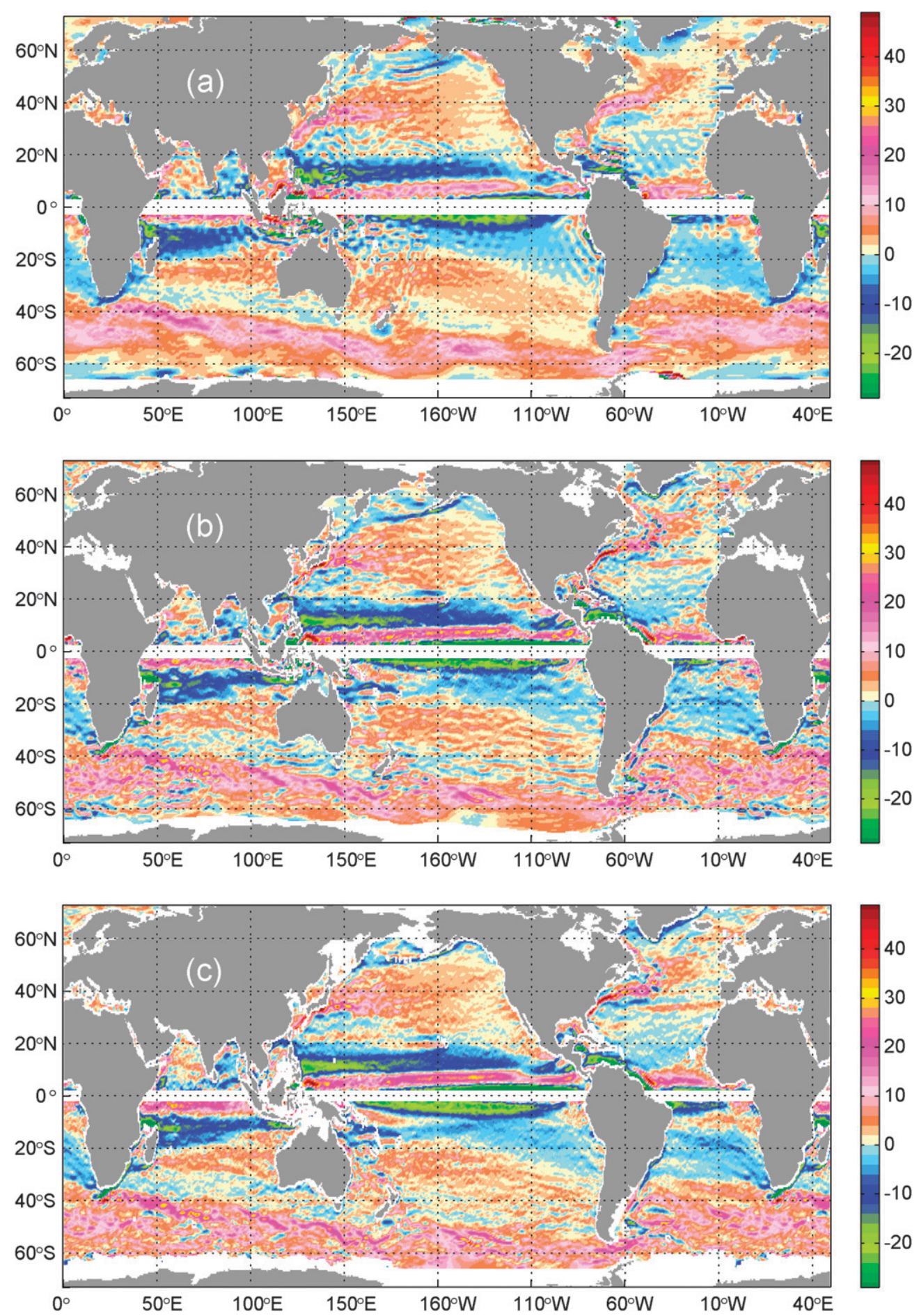

FIG. 5. The mean geostrophic zonal velocities computed from (a) $\bar{\eta}_{A}$, (b) $\bar{\eta}_{B}$, and (c) $\bar{\eta}_{C}$ shown in Fig. 1.

are seen to continue eastward as series of at least four branches each. The North Pacific and the North Atlantic Currents are now seen as semiorganized series of zonal concentrations of eastward flow, rather than a broad eastward drift. Similar features are also seen in the eastward flowing limbs of the South Pacific and South Indian Ocean subtropical gyres.

A number of well-defined striations extend seaward several thousand kilometers from the western continental margins of North America, South America, and southern 
Africa. Along the California coast, these have roots in the permanent meanders of the California Current System, which appear to be caused by the seaward influence of its semipermanent meanders (Centurioni et al. 2008). Off the California coast, as well as off the coast of Chile, the depth structure of these near-zonal flows appears also in historical hydrographic data (Maximenko et al. 2008). The depth structure of the strong eastward St. Helena Current, which approaches the tip of South Africa from the west, also appears in historical files (Juliano and Alves 2007). Figure 5 presents a new context in which to view the continued datasets from satellites and drifters. Results of the Gravity Field and Steady-State Ocean Circulation Explorer (GOCE) mission (available online at http://www.esa.int/esaLP/LPgoce.html) are anticipated to further improve the gravity model, and observations currently being made by over 3000 Argo profiling floats (available online at http://www.argo.ucsd.edu) will extend the refined pattern of the mean circulation into the interior of the ocean.

Acknowledgments. This work was supported by the NASA Ocean Surface Topography Science Team and NASA GRACE Science Team. N.M. and O.M. were also supported by NSF Grant OCE05-50853, the Japan Agency for Marine-Earth Science and Technology (JAMSTEC), NASA through Grant NNX07AG53G, and NOAA through Grant NA17RJ1230. NASA and NOAA sponsor research at the International Pacific Research Center. B.G. was partly supported by ARO Grant W911NF-05-1-0055 and ONR Grant N00014-07-11065. Satellite altimetry data were acquired from the Aviso and drifter data from the NOAA AOML. Help of Dr. Yoo-Yin Kim is gratefully acknowledged.

\section{REFERENCES}

Centurioni, L. R., J. C. Ohlmann, and P. P. Niiler, 2008: Permanent meanders in the California Current System. J. Phys. Oceanogr., 38, 1690-1710.

Crosby, D. S., L. C. Breaker, and W. H. Gemmill, 1993: A proposed definition for vector correlation in geophysics: Theory and application. J. Atmos. Oceanic Technol., 10, 355-367.

Ducet, N., P. Y. LeTraon, and G. Reverdin, 2000: Global highresolution mapping of ocean circulation from TOPEX/ Poseidon and ERS-1 and -2. J. Geophys. Res., 105 (C8), 19 477-19 489.

Gill, A. E., 1982: Atmosphere-Ocean Dynamics. Academic Press, $662 \mathrm{pp}$.

Guinehut, S., 2002: Vers une utilisation combinée des données altimétriques et des mesures des flotteurs profilants. Ph.D. thesis, Université Paul Sabatier, 168 pp.

- and G. Larnicol, 1999: Impact de la salinité dans le calcul des hauteurs dynamiques-Etude effectuée à partir des sections WOCE de l'océan Atlantique. Collecte Localisation Satellites Contract CNES/CLS 794/98/CNES/7235, 27 pp.
Hernandez, F., P. Schaeffer, M.-H. Calvez, J. Dorandeu, Y. Faugere, and F. Mertz, 2001: Surface Moyenne Oceanique: Support Scientifique à la mission altimetrique Jason-1, et à une mission micro-satellite altimétrique. Collecte Localisation Satellites Final Rep. CLS/DOS/NT/00.341, 150 pp.

Hughes, C. W., 2005: Nonlinear vorticity balance of the Antarctic Circumpolar Current. J. Geophys. Res., 110, C11008, doi:10.1029/2004JC002753.

Imawaki, S., H. Uchida, H. Ichikawa, M. Fukasawa, and S. Umatani, ASUKA Group, 2001: Satellite altimeter monitoring the Kuroshio Transport south of Japan. Geophys. Res. Lett., 28, 17-20.

Juliano, M. F., and M. L. G. R. Alves, 2007: The Atlantic subtropical front/current systems of Azores and St. Helena. J. Phys. Oceanogr., 37, 2573-2598.

Large, W. G., 1998: Modeling and parameterizing the ocean planetary boundary layer. Ocean Modeling and Parameterization. E. P. Chassignet and J. Verron, J., Eds., Kluwer Academic, 81-120.

Levitus, S., and Coauthors, 1998: Introduction. Vol. 1, World Ocean Database 1998. NOAA Atlas NESDIS 18, 346 pp.

Mann, C. R., 1967: The termination of the Gulf Stream and the beginning of the North Atlantic Current. Deep-Sea Res., 14, 337-359.

Maximenko, N. A., and P. P. Niiler, 2005: Hybrid decade-mean global sea level with mesoscale resolution. Recent Advances in Marine Science and Technology, 2004, N. Saxena, Ed., PACON International, 55-59.

— , and - 2008: Tracking ocean debris. IPRC Climate, Vol. 8, No. 2, International Pacific Research Center, 14-16. [Available online at http://iprc.soest.hawaii.edu/publications/newsletters/ newsletter_sections/iprc_climate_vol8_2/tracking_ocean_debris. pdf.]

_, O. V. Melnichenko, P. P. Niiler, and H. Sasaki, 2008: Stationary mesoscale jet-like features in the ocean. Geophys. Res. Lett., 35, L08603, doi:10.1029/2008GL033267.

Nerem, R. S., B. D. Tapley, and C. K. Shum, 1990: Determination of the ocean general circulation using Geosat altimetry. J. Geophys. Res., 95 (C3), 3163-3179.

Niiler, P. P., 2001a: The world ocean surface circulation. Ocean Circulation and Climate, G. Siedler, J. Church, and J. Gould, Eds., Academic Press, 193-204.

_ 2001b: Global ocean circulation observations. Observing the Oceans in the 21st Century, C. J. Koblinsky and N. R. Smith, Eds., Australian Bureau of Meteorology, 306-323.

—, D. K. Lee, W. Young, and L. H. Hu, 1991: Expendable current profiler (XCP) section across the North Pacific at $25^{\circ}$ N. Deep-Sea Res., 38, S45-S61.

_ S. Piacsek, L. Neuberg, and A. Warn-Varnas, 1992: Scales of SST variability of the Iceland-Faeroe Front. J. Geophys. Res., 97 (C11), 17 777-17 785.

_ N. A. Maximenko, and J. C. McWilliams, 2003: Dynamically balanced absolute sea level of the global ocean derived from near-surface velocity observations. Geophys. Res. Lett., 30, 2164, doi:10.1029/2003GL018628.

Ochoa, J., and P. P. Niiler, 2007: Vertical vorticity balance in meanders downstream the Agulhas retroflection. J. Phys. Oceanogr., 37, 740-744.

Pascual, A., Y. Faugère, G. Larnicol, and P.-Y. Le Traon, 2006: Improved description of the ocean mesoscale variability by combining four satellite altimeters. Geophys. Res. Lett., 33, L02611, doi:10.1029/2005GL024633.

Pazan, S. E., and P. Niiler, 2004: New global drifter data set available. Eos, Trans. Amer. Geophys. Union, 85, doi:10.1029/ 2004EO020007. 
Ralph, E. A., K. Bi, P. P. Niiler, and Y. A. du Penhoat, 1997: A Lagrangian description of the western equatorial Pacific response to the wind burst of December 1992: Heat advection in the warm pool. J. Climate, 10, 1706-1721.

Reigber, C., R. Schmidt, F. Flechtner, R. König, U. Meyer, K.-H. Neumayer, P. Schwintzer, and S. Y. Zhu, 2005: An Earth gravity field model complete to degree and order 150 from GRACE: EIGEN-GRACE02S. J. Geodyn., 39, 1-10.

Reverdin, G., P. P. Niiler, and H. Valdimarsson, 2003: North Atlantic Ocean surface currents. J. Geophys. Res., 108 (C1), 3002-3004.

Richardson, P. L., 1989: Worldwide ship drift distributions identify missing data. J. Geophys. Res., 94, 6169-6176.

Rio, M.-H., and F. Hernandez, 2003: High-frequency response of wind-driven currents measured by drifting buoys and altimetry over the world ocean. J. Geophys. Res., 108, 3283, doi:10.1029/2002JC001655.

—_ and _- 2004: A mean dynamic topography computed over the world ocean from altimetry, in situ measurements, and a geoid model. J. Geophys. Res., 109, C12032, doi:10.1029/ 2003JC002226.

_, P. Schaeffer, and J. M. Lemoine, 2005: The estimation of the ocean mean dynamic topography through the combination of altimetric data, in-situ measurements and GRACE geoid: From global to regional studies. Proc. GOCINA Int. workshop, Luxembourg, Centre Européen de Géodynamique et de Séismologie.

Robinson, A. R., Ed., 1983: Eddies in Marine Science. SpringerVerlag, $609 \mathrm{pp}$

Rudnick, D. L., 1996: Intensive surveys of the Azores Front 2. Inferring the geostrophic and vertical velocity fields. J. Geophys. Res., 101, 16 291-16 303.

Schmitz, W. J., and P. L. Richardson, 1991: On the sources of the Florida Current. Deep-Sea Res., 38 (Suppl.), 389-409.
Siedler, G., J. Church, and J. Gould, Eds., 2001: Ocean Circulation and Climate. Academic Press, 715 pp.

Stammer, D., 1997: Global characteristics of ocean variability estimated from regional TOPEX/Poseidon altimeter measurements. J. Phys. Oceanogr., 27, 1743-1769.

Sverdrup, H. U., M. W. Johnson, and R. H. Flemming, 1942: The Oceans: Their Physics, Chemistry, and General Biology. Prentice-Hall, 1087 pp.

Tapley, B. D., D. P. Chambers, S. Bettadpur, and J. C. Ries, 2003: Large scale ocean circulation from the GRACE GGM01 Geoid. Geophys. Res. Lett., 30, 2163, doi:10.1029/2003GL018622.

— S. Settadpur, M. Watkins, and C. Reigber, 2004: The Gravity Recovery and Climate Experiment: Mission overview and early results. Geophys. Res. Lett., 31, L09607, doi:10.1029/ 2004GL019920.

Uchida, H., and S. Imawaki, 2003: Eulerian mean surface velocity field derived by combining drifter and satellite altimeter data. Geophys. Res. Lett., 30, 1229, doi:10.1029/2002GL016445.

- — - and J.-H. Hu, 1998: Comparison of Kuroshio surface velocities derived from satellite altimeter and drifting buoy data. J. Oceanogr., 54, 115-122.

Uda, M., and K. Hasunuma, 1969: The eastward subtropical countercurrent in the western North Pacific Ocean. J. Oceanogr. Soc. Japan, 25, 201-210.

Wunsch, C., and E. M. Gaposchkin, 1980: On using satellite altimetry to determine the general circulation of the oceans, with application to geoid improvement. Rev. Geophys., 18, 725-745.

Xie, S.-P., W. T. Liu, Q. Liu, and M. Nonaka, 2001: Far-reaching effect of the Hawaiian Islands on the Pacific Ocean-atmosphere system. Science, 292, 2057-2060.

Zlotnicki, V., and J. G. Marsh, 1989: Altimetry, ship gravimetry, and the general circulation of the North Atlantic. Geophys. Res. Lett., 16, 1011-1014. 